\title{
Keynote address: efficient use of energy
}

\author{
K. Traa \\ Kjell Traa Consulting, Stavanger, Norway
}

\begin{abstract}
All primary energy sources, such as oil, gas, coal, nuclear and hydro need to be converted into end-user energy services known as mechanical work, electricity, heating and cooling. In the process of conversion, only a portion of the primary energy is transformed into the new form, while the rest remains unaltered and is lost.

The various forms of energy services produced represent a different value or quality, e.g. heat holds an energy quality ranging from 0 and upwards, depending on the temperature difference which is utilized, as defined by the second law of thermodynamics. Energy efficiency in this context may also be defined as the ratio between energy quality output and input.

Practically all fossil fuels are converted to energy services via combustion and heat, i.e. the conversion efficiency is solely determined by temperatures, meaning that high energy efficiency can only be obtained at large temperature differences, such as in power generation, while ordinary domestic heating will yield a very low efficiency.

Given that some $30-40 \%$ of all fossil fuels today are used for domestic heating, representing an end-user energy quality of (say) 1/10 of what is obtained in modern power generation, there is a tremendous potential globally for energy efficiency improvements, not to mention the associated emissions reductions.

The obvious solution is to pay more attention to the second law of thermodynamics, i.e. to shift from direct combustion heating to thermodynamic principles, e.g. by use of electrical driven heat pumps and/or combined heat and power as another alternative.
\end{abstract}

Keywords: energy, exergy, efficiency, thermodynamics, heat, power, electricity. 


\section{Introduction}

As we all know, for the world as a whole, it's all about energy, in one form or the other. But within the framework of this keynote I will limit myself to human life and activities.

Nature has provided mankind with abundant sources of energy, as reserves stored in the underground and the several direct sources delivered or driven by the daily influx of energy from the sun.

Human life and work depends on a continuous supply of energy and with increasing world population and technological progress, the demand for energy has now grown to a level where it risks putting our future at stake.

Since the industrial revolution really took off, more than 100 years ago, the dominating energy supply has come from non-renewable fossil fuels (coal, oil, natural gas), accounting for more than $80 \%$ of total supply, while the remaining demand is covered by hydro, nuclear and other renewable energy sources (bio fuels, wind power, geothermal heat, solar, tidal power, etc.).

The steep increase in use of fossil fuels over the past decades, has for some time already been causing grave concern, not only the consequences of dwindling reserves, but primarily the negative environmental impact, caused by burning of hydrocarbons.

A root cause to all this is the enormous waste of energy which is still taking place on earth, despite well known knowledge which tells us how to do better.

The energy loss is inextricably linked to energy conversion, as illustrated in fig. 1 .

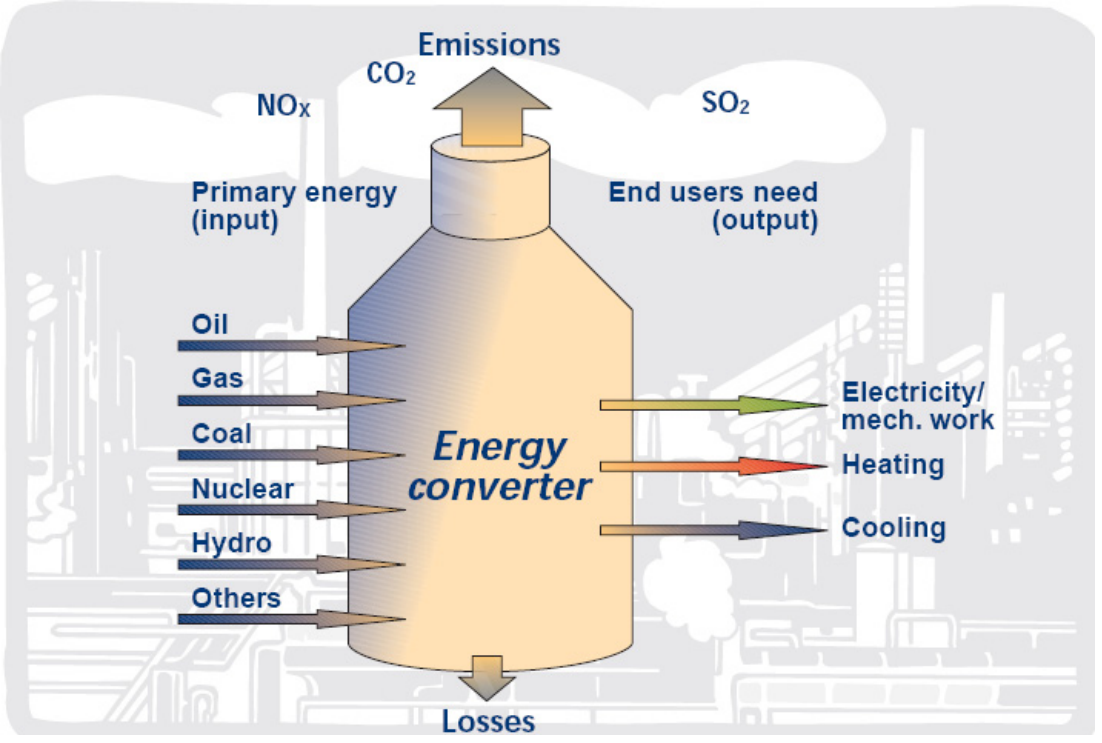

Figure 1: Conversion of primary energies to end-user energy services. 
All primary energy sources need to be converted to end user energy services (such as mechanical work, electricity, heating and cooling), and conversion of primary energies suffer from losses, as well as harmful emissions, for fuels which are converted via combustion.

End user energy services are ranked according to their quality (as we will revert to later), with electricity at the top of the scale and ordinary domestic heating at the bottom.

Given that some $30-40 \%$ of all fossil fuels today are used for ordinary heating, representing an end-user energy quality of (say) 1/10 of what is obtained in modern power generation, there is a tremendous potential globally for energy efficiency improvements, not to mention the associated potential emissions reductions.

Improvements in energy efficiency therefore is among the top-ranked measures in several official international/national action plans, to curb the global warming trend, such as EU's "Energy Roadmap 2050" (on 15 December 2011, the European Commission adopted the Communication "Energy Roadmap 2050 ", whereby the EU is committed to reducing greenhouse gas emissions to $80-95 \%$ below 1990 levels by 2050, in the context of necessary reductions by developed countries as a group) and the UK "Carbon Plan 2050". (The UK Carbon Plan, published in December 2011, sets out the Government's plans for achieving the emissions reductions committed to in the first four carbon budgets, on a pathway consistent with meeting the 2050 target.)

\section{Energy definitions and terms}

Energy may be defined as "ability to do work", or as ability or potential to make something happen.

Further, energy exists in several forms, such as

- chemical energy stored in a substance and which can be released by a chemical reaction (e.g. by burning of a fuel)

- mechanical energy or electricity (which effectively is a form of work)

- potential energy (e.g. a water fall or energy stored in a spring)

- heat, e.g. for heating, melting or evaporating of a substance

- light, and several more.

Since in the order of some $90 \%$ of the global energy supply is derived from conversion to heat, we will in the following concentrate on heat based energy services.

Conversion of heat to energy services (such as mechanical work, electricity or various heating purposes), is subject to the laws of thermodynamics. The first law is about conservation of energy, stating that energy is neither created nor destroyed, but merely changed from one form to another. (An exception to this first law is nuclear reactions only, where matter is converted to energy.)

It is quite common to speak about "energy consumption", but such expression is of course meaningless, since energy cannot be consumed or disappear; it can merely be utilized during its inexorable drop from higher to lower temperature, until it ends up as heat dissipated to the environment (air, water, soil). 
The proportion of energy that can be exploited is defined by the second law of thermodynamics, stating that heat cannot be converted directly into mechanical work (which is one of several definitions of the second law).

The part of an amount of heat energy that may be transformed into mechanical work is determined by the temperatures where the heat is supplied, respectively emitted.

This is expressed in the following equation, for an ideal loss free process:

where:

$$
\mathrm{W}=\mathrm{Q} \times(\mathrm{T} 1-\mathrm{T} 2) / \mathrm{T} 1
$$

$\mathrm{W}=$ Mechanical work obtained, also called "Exergy"

$\mathrm{Q}=$ Heat supplied

$\mathrm{T} 1=$ Absolute temperature $(\mathrm{K})$ of heat supplied

$\mathrm{T} 2=$ Absolute temperature $(\mathrm{K})$ of heat emitted.

When T2 equals ambient temperature, maximum mechanical work (Wmax), is obtained.

Wmax then is the theoretical maximum amount of useful mechanical work that can be extracted from a given amount of heat.

The above equation and expressions related to the second law of thermodynamics are illustrated in fig. 2 .

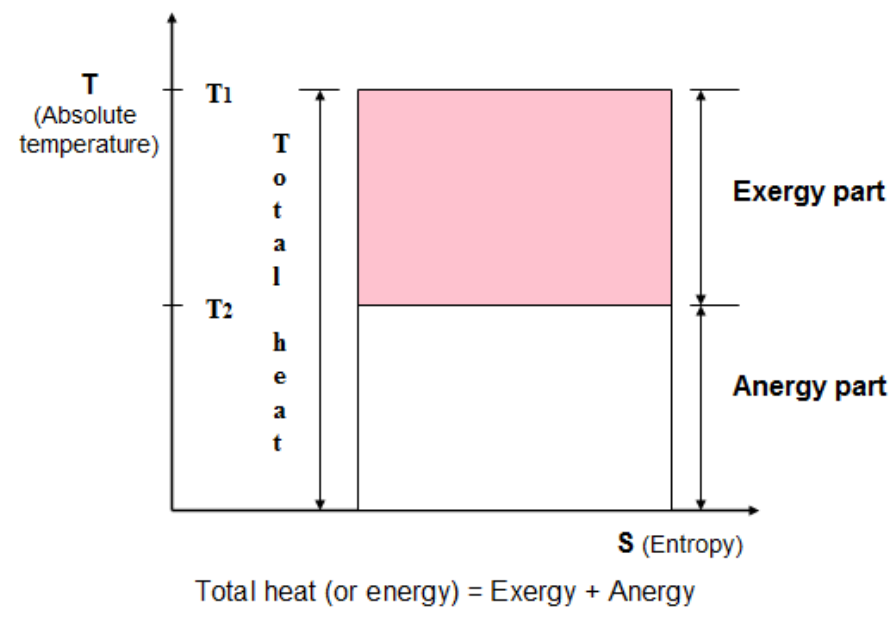

Figure 2: Temperature-entropy diagram for an ideal loss-free process, where heat is supplied/emitted at constant temperature.

\section{It's all about exergy}

As we have seen from fig. 2, energy consists of two elements, according to the equation:

$$
\text { Energy }=\text { Exergy }+ \text { Anergy }
$$


Exergy is the part of energy which is valuable and at the same time is a measure of the quality of an energy service, while the Anergy part makes up the losses and therefore has no value.

In contrast to energy in general (which can neither be created nor destroyed), exergy (or energy quality) will be consumed in all energy transformations.

When converting heat produced from primary energies, the exergy recovery depends on the temperature drop which is utilized and this is in principle similar to hydro power, where:

- the water flow (mass) corresponds to the flow of thermal energy (kcal or $\mathrm{kWh}$ ), and;

- the water fall height corresponds to the temperature drop in a thermal system

In both cases, the challenge is to capture as much exergy as possible out of water fall height, respectively the temperature drop in a flow of heat.

The exergy content determines the quality of an energy service, with mechanical work and electricity ranked at the top of the quality scale, both representing practically pure exergy, while the quality of various heating services (steam and other heating measures), depends on the temperature, as shown in fig. 3, where $0^{\circ} \mathrm{C}$ is used as ambient temperature and the exergy content is computed using the second law equation as explained above.

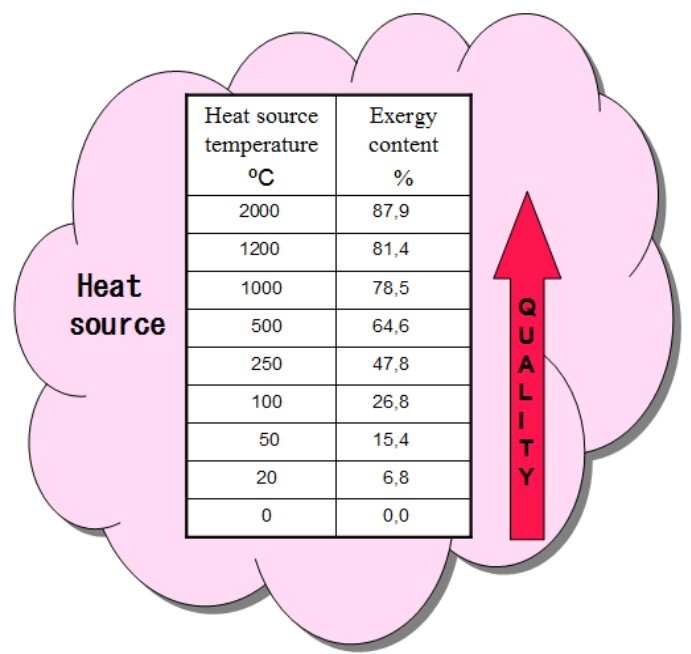

Figure 3: Exergy content of heat as a function of temperature.

Looking at the exergy numbers in fig. 3 it is worthwhile to take note of the following:

- At the upper end: heat supply at $1200^{\circ} \mathrm{C}$ coincides roughly with today's maximum allowable inlet temperature in a modern gas power plant, due to material constraints. Consequently, one way to improve the exergy efficiency (also called the thermal efficiency of a power plant), beyond 
today's maximum of about $60 \%$ (for large combined cycle power plants), would be to raise the inlet temperature, and this is likely to happen along with the further development of heat resistant materials.

- At the lower end: For ordinary domestic heating with heat supply at $20^{\circ} \mathrm{C}$ room temperature and assuming $0^{\circ} \mathrm{C}$ as outdoor (ambient) temperature, the exergy content is reduced to $6.8 \%$ only. Consequently, when using primary fuels or electricity to provide a low quality energy service, such as ordinary house heating, we suffer a tremendous loss of useful energy.

A main challenge in energy management is to be aware that the degradation of energy quality (i.e. exergy), is permanent and irreversible and in contrast to energy and the first law of thermodynamics.

In simple terms it means to adapt the quality of the energy source to the actual service, for the purpose of minimizing losses and emissions.

\section{Illustration of energy vs. exergy accounts}

Figure 4 shows 5 different energy applications with related flows of energy respectively exergy.
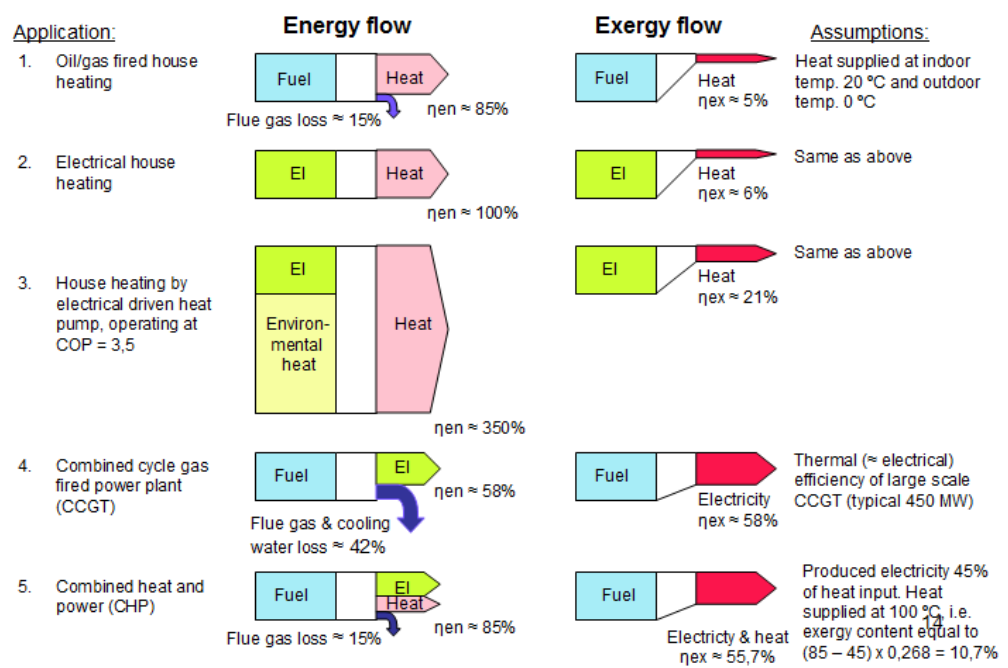

Figure 4: Energy vs. exergy flow for different applications.

The various options warrant some further explanations and comments, as follows:

Application 1: When burning a fossil fuel, such as oil or gas, for ordinary house heating, a fraction only of the fuel exergy (100\%), is required in order to maintain a temperature difference of 20 degrees (used as an example), between indoor and outdoor temperatures. 
As shown in the table in fig. 3, the exergy content at $20^{\circ} \mathrm{C}$ is $6.8 \%$ only (theoretical) and may be rounded off to $6 \%$ due to losses, i.e. the final exergy recovery will be $6 \% \times 0.85 \approx 5 \%$.

Application 2: The use of electricity for direct heating is also extremely inefficient, but since all electricity is converted to heat, the exergy recovery at the same temperature conditions as in Application 1, is now about $6 \%$.

Application 3: An electrical driven heat pump will deliver heat according to its COP (Coefficient of Performance). In this case with COP $=3.5$, the exergy recovery will be equal to Application 2 times 3.5, i.e. $6 \%$ x $3.5=21 \%$.

Application 4: A large modern gas fired combined cycle power plant is able to convert up to about $58 \%$ of the energy supplied into electricity (which is $100 \%$ exergy), depending on climatic conditions (air and cooling water temperatures). The main performance constraint is the temperature at the inlet of the gas turbine, currently limited to $1100-1200^{\circ} \mathrm{C}$, due to material constraints.

Application 5: Combined heat and power (CHP) is an option when there is a stable need for heat (e.g. in the form of hot water or steam), for domestic or industrial purpose close to the plant. The split between power and heat depends on the exact circumstances. By optimization, selecting a split e.g., as indicated in this example, it is possible to obtain an exergy efficiency comparable to a combined cycle power plant.

\section{Misconceptions about energy and efficiency}

There are unfortunately many misconceptions and outright errors concerning energy matters, mainly due to lack of knowledge, in today's society.

This is most serious, in particular when decision makers within energy policies and management, demonstrate ignorance, such as arguing that direct burning of fuel for heat is more energy efficient than power generation.

As we have demonstrated above, this is actually turning facts upside down, since conversion to electricity is by far the most efficient way to utilize fuels, while direct firing for domestic heating is the least effective option.

Arguing that combined heat and power (CHP) yields higher efficiency than pure power generation, by simply counting units $(\mathrm{kWh})$ of electricity and heat as equal. However, in order to calculate correctly on an equal basis, it is the exergy content of both services which need to be added.

The indiscriminate use of $\mathrm{kWh}$ as unit in sales of energy, regardless of the quality of the energy source.

As an example (published in Norway): the energy content of gas sold in a month is equal to twice the annual Norwegian hydro power production.

Obviously, a serious misconception to compare directly the calorific value of gas produced with produced hydro-electrical kWhs (if such a comparison should be meaningful, one had to assume that the gas was first converted to power and 
assuming an average electrical efficiency of (say) $50 \%$, the answer would be that the Norwegian gas production in one month, on equal terms, might be comparable to half of the annual Norwegian hydro power production).

Another frequently used term is energy consumption, but as we know from the first law of thermodynamics, energy cannot be consumed (in the sense that it will disappear); it can only be utilized through conversion.

And the overall challenge in all such utilization of energy is to harvest as much of the precious exergy as possible, before it all ends up as anergy (ambient heat).

\section{Strategies for efficient energy household}

All future primary energy demand projections point in the same upward direction, indicating a growth of at least one-third over the next $20+$ years, as illustrated in fig. 5.

\section{World primary energy demand}

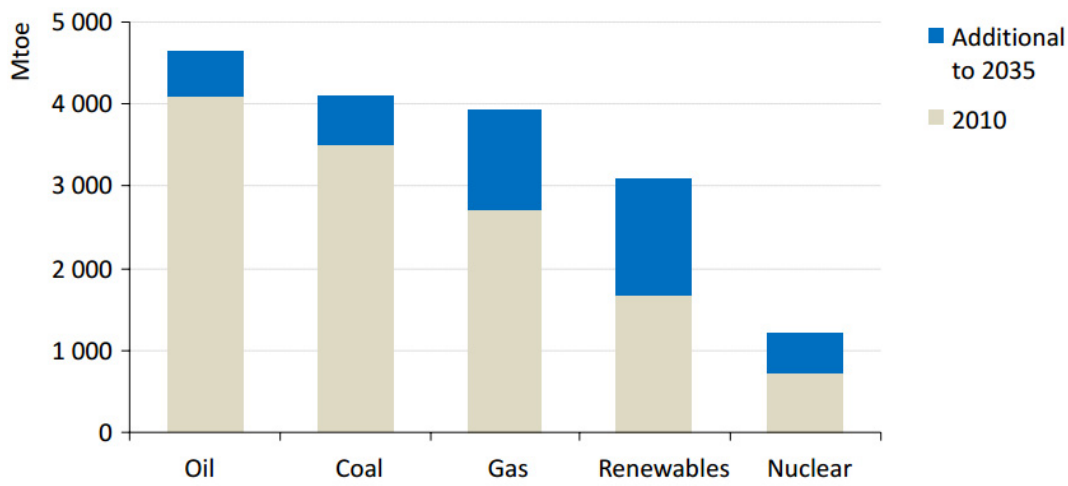

Figure 5: World Energy Outlook 2011 showing primary energy demand increases by one-third between 2010 and 2035. (Source: IEA.)

Securing supply to meet such increased demand is in itself a major challenge, but to deal with the increased $\mathrm{CO}_{2}$ emissions is by far the most serious issue and so far we can only speculate on what the consequences will be, except that we pretty well know as a fact that we are facing global warming.

To cope with this situation there is unfortunately one prescription only: The emissions from hydro carbon fuels must be brought under control, but this is easier said than done, considering the steep projected increase in global demand of $\mathrm{CO}_{2}$ emitting fuels.

Among the several $\mathrm{CO}_{2}$ reducing measures which are wished/planned/ researched/available, increased energy efficiency stands out as one of the most realistic and effective measures.

Ironically enough, knowledge as well as technologies related to energy efficiency measures are well known, in contrast to emission reducing measures, 
such as $\mathrm{CO}_{2}$ removal and sequestration, where technical solutions are still at research and testing levels.

It is therefore imperative that improvements in energy efficiency are further strengthened and remain as top-ranked measures to curb the galloping negative trend related to energy, emissions and global warming.

Strategies for implementing more efficient use of energy should be based on the following key issues and assumptions:

- Primary energies used directly for ordinary domestic heating, represent an enormous waste of exergy and should be replaced by thermodynamic heating principles, e.g. electrical driven heat pumps and CHP (Combined Heat and Power). Potential gains within this segment of energy supply are tremendous, knowing that $30-40 \%$ of all fossil fuels today are used for ordinary low quality heating services, with an exergy efficiency in the order of 5-6\% only.

- An overriding first priority should be to focus on electricity, in conversion of primary energies into end-user energy services, thus securing the highest possible exergy efficiency. It is important to keep in mind that electricity really meets all end user needs (light, mechanical work, heating, cooling, IT services, etc.).

- As a consequence of the above: Energy distribution by wire only should be preferred, rather than a double system by parallel installation of a gas distribution grid. In countries where gas distribution already is widespread, priority could be on local CHP, in sizes down to small scale gas fired household CHP. Building of new residential gas distribution infrastructure should be rejected.

- In order to further improve the exergy recovery in power generation, priority should be on development of materials which will allow gas turbine inlet temperatures beyond today's maximum of $1100-1200^{\circ} \mathrm{C}$ and thus obtain thermal efficiencies above $60 \%$.

- Likewise, priority should be on further development of "reversible" heat pumps, suitable for heating as well as refrigeration services, targeting COP (for heating) well beyond today's 3.5-4, up to (say) 5-6, meaning that an exergy efficiency in excess of $30 \%$ for ordinary heating, might be obtained.

- Replace conventional lighting with LED (light-emitting diode) lighting, thus obtaining $70-80 \%$ energy saving. Knowing that some $20 \%$ of today's electricity production worldwide is used for lighting, the energy (or more correctly: exergy) saving potential by use of LED lighting, is enormous.

\section{Concluding remarks}

The massive waste of energy which is taking place worldwide needs to be curbed, in order to reduce the alarming negative consequences, notably the emissions of $\mathrm{CO}_{2}$ from fossil fuels, causing global warming. 
As we have demonstrated in the foregoing, the potential for fuel saving as a result of increased energy efficiency is formidable and it is therefore not surprising that this measure alone is among the top ranked priorities in the climate debate.

The benefits of fuel saving are obvious, but realizing its full potential (which really is needed in order to meet current climate targets), also means reduced energy demand, and how will the energy industry cope with that? In today's world the recipe for successful industrial and economic progress is to stay on an upward trend, but for the energy industry in a sustainable future development, it would have to mean that the trend curve will stagnate and then bend downwards.

Adding all of the opportunities for energy efficiency improvement together, it will make a significant contribution to energy conservation and emissions reductions. As example: EU has put up as target to increase the overall energy efficiency by $20 \%$ by 2020 .

However, implementation of energy efficiency measures are in general far too slow, despite the fact that knowledge and technology has been known for a very long time. Just think of the thermodynamic laws and the Carnot cycle, all originating from the $19^{\text {th }}$ century !!

A main cause for the slow progress is lack of basic knowledge among a majority of energy officials and decision makers, and what can be done about that?

Universities have in this context an important role to play in dissemination of basic and practical energy related knowledge to students, media, authorities, the energy industry etc.

\section{References}

[1] Simpson, M., Kay, J. J., “Availability, Exergy , the Second Law and all that ....", 1989 http://groups.yahoo.com/group/energyresources/message/35950

[2] Schneider, E. D., Kay, J. J., "Complexity and Thermodynamics: Towards a New Ecology”, Futures 24 (6) pp. 626-647, August 1994 